\title{
Perceptions of Tobacco Control Media Campaigns Among Smokers With Lower Socioeconomic Status
}

\author{
Anna McCullough, MSW, MSPH ${ }^{1}$ \\ Clare Meernik, $\mathrm{MPH}^{1}$ \\ Hannah Baker, $\mathrm{MPH}^{1}$ \\ Kristen Jarman, $\mathrm{MSPH}^{1}$ \\ Barbara Walsh, BS ${ }^{2}$ \\ Adam O. Goldstein, MD, $\mathrm{MPH}^{1}$
}

People with low socioeconomic status (SES) in the United States have disparately high rates of smoking and experience disproportionately high burdens of smokingrelated disease. Tobacco control media campaigns are a critical strategy for reducing tobacco use prevalence, but evidence is mixed about the optimal use of mass media to reach and promote tobacco use cessation among people with low SES. Improved understanding of the factors influencing how low-SES tobacco users evaluate tobacco control media campaigns may inform development of more effective messages and strategies. Focus groups with primarily low-SES smokers in Connecticut were conducted, finding that participants had seen many tobacco control television ads that used graphic imagery and testimonials, but participants voiced two main themes that limited ad effectiveness: (1) skepticism about the content of ads, the role of the tobacco industry and the government in sponsoring the ads, and the safety and efficacy of cessation supports; and (2) barriers to quitting such as stress, social contexts, and addiction that participants perceived as being underappreciated in the context of the ads. Tobacco control media campaigns targeting low-SES tobacco users may need additional messages, tools, or refinements to more optimally motivate this group to make quit attempts.

Keywords: tobacco; tobacco cessation; media campaigns; socioeconomic status; health communication

Health Promotion Practice

July 2018 Vol. 19, No. (4) 550-559

DOI: $10.1177 / 1524839917741485$

\section{INTRODUCTION}

Overall prevalence of tobacco use has decreased in the United States, yet rates remain disproportionately high among people with low socioeconomic status (SES). The prevalence of any tobacco use among adults is estimated at $21.3 \%$ overall, with higher rates among adults with a GED (50\%) and adults with annual income less than $\$ 20,000(32.2 \%$; Hu et al., 2016). People with low SES smoke more heavily than those with higher SES (Hiscock, Bauld, Amos, Fidler, \& Munafò, 2012), which contributes to increased risk of tobacco-related diseases (Clegg et al., 2009; Mucha, Stephenson, Morandi, \& Dirani, 2006). While tobacco users with low SES are as likely to make quit attempts as those with higher SES, they have lower rates of success (Kotz \& West, 2009) and are more likely to make unaided quit attempts (McCarthy, Siahpush, Shaikh, Kessler, \& Tibbits, 2016). Higher use and lower cessation success rates may be a result of unique challenges faced by tobacco users with low SES, including tobacco industry targeting (Hiscock et al., 2012), more prosocial smoking cues (Paul, Turon, Bonevski, Bryant, \&

\footnotetext{
${ }^{1}$ University of North Carolina at Chapel Hill, Chapel Hill, NC, USA

${ }^{2}$ Connecticut Department of Public Health, Hartford, CT, USA
}

Authors' Note: Focus groups were funded by the Connecticut Department of Public Health. Findings and ideas presented in this article are those of the authors and do not represent the Connecticut Department of Public Health. Address correspondence to Clare Meernik, 200 N. Greensboro Street, CB \#7424, Carrboro, NC 27510, USA; e-mail: cmeernik@email.unc.edu. 
McElduff, 2013), less access to workplace-based smokefree policies or smoking cessation resources (Ham et al., 2011), self-exempting beliefs about the effects of tobacco use (Oakes, Chapman, Borland, Balmford, \& Trotter, 2004), high stress and use of smoking as a perceived stress management tool (Hiscock et al., 2012), higher levels of nicotine dependence, and lower self-efficacy related to quitting (Siahpush, McNeill, Borland, \& Fong, 2006). Historical lack of access to smoke-free housing may also contribute to lower cessation rates among this population, though a recent policy by the Department of Housing and Urban Development requiring all public housing to become smoke-free may attenuate this particular barrier (Geller, Rees, \& Brooks, 2016).

Population level mass media campaigns are a wellestablished, effective strategy for reducing tobacco use prevalence (Durkin, Brennan, \& Wakefield, 2012) and are recommended as a tobacco control best practice (Centers for Disease Control and Prevention [CDC], 2014). Mass media campaigns use various communication channels, including television, radio, print, and/or out-of-home (e.g., billboard) advertising (Durkin et al., 2012). Campaigns are most effective when integrated with a comprehensive tobacco control program including community interventions and cessation activities (CDC, 2014). However, the evidence is somewhat mixed about the impact and optimal use of mass media to promote use of cessation programs and cessation among tobacco users with low SES (Durkin et al., 2012; Niederdeppe, Kuang, Crock, \& Skelton, 2008), but possible differences in effectiveness for this group may be related to campaign exposure, motivational response, and/or opportunities to sustain long-term cessation (Niederdeppe et al., 2008).

The CDC (2014) highlights the importance of creating messages that resonate with a given priority audience, and there is evidence that ads focusing on negative health consequences and using personal testimonials, graphic imagery, and/or negative emotion may contribute to overall campaign effectiveness among low-SES smokers (Durkin et al., 2012; Niederdeppe, Farrelly, Nonnemaker, Davis, \& Wagner, 2011). The CDC-funded national mass media Tips From Former Smokers (Tips) advertising campaign used this approach and has been associated with increases in quitline call volume across most states and demographic groups (Zhang, Malarcher, et al., 2015; Zhang, Vickerman, Malarcher, \& Carpenter, 2015), resulting in increases in population-level quit attempts (McAfee, Davis, Alexander, Pechacek, \& Bunnell, 2013). However, the effectiveness of the Tips campaign specifically on smokers with low SES has not been established.
Rimal and Lapinski (2009) describe a health communication framework characterized by James Carey as involving both the transmission of messages (i.e., transmission view) and the receipt and evaluation of messages by individuals (i.e., ritual view). This dual view of communication asserts that individual and social factors (e.g., personal experiences, efficacy beliefs, social norms) influence the communication efforts people encounter and the meaning they take away from those communications (Rimal \& Lapinski, 2009). This framework suggests that improved understanding of the factors that influence how low-SES smokers evaluate tobacco control ads may support the development of messages that more effectively engage this population.

To that end, we present findings from focus groups conducted as part of an independent evaluation of the Connecticut Tobacco Control Program designed to inform the program's mass communication strategies and other cessation resources. Connecticut launched an 11-month tobacco control campaign in November 2013 that included a mix of English and Spanish language Tips ads on TV, radio, print, online, and out-ofhome venues. All ads were tagged with the quitline number and website, intending to drive callers to the Connecticut Quitline, which offers tobacco users in Connecticut five counseling calls and 2 weeks of free nicotine replacement therapy (NRT). Connecticut's mass communication efforts attempted to reach several priority populations, including tobacco users with low SES, and focus group recruitment was designed to achieve representation from these populations. In our initial analysis of these data, which focused on questions specific to program planning and evaluation, we identified an unanticipated body of data relating to how participants' experiences and beliefs influenced their receipt and evaluation of tobacco cessation media messages.

\section{METHOD}

Focus groups were designed to inform program planning for the Connecticut Tobacco Control Program, rather than as data collection for a formal qualitative study. Methodological decisions about recruitment and focus group implementation reflect the primary purpose of the groups; decisions related to data analysis are informed by a thematic analysis approach (Braun \& Clarke, 2006), adapted to address the limitations inherent in conducting a formal qualitative analysis on data collected in the context of real-world public health program planning. 


\section{Participant Recruitment}

Eligible participants were adults age 18 or older who reported current cigarette smoking; eligibility criteria were intentionally broad to facilitate adequate participation. Focus groups were held over a 2-day period in September 2014. Recruitment flyers and radio ads directed interested participants to complete eligibility screening via a website or a toll-free number. One member of the research team conducted in-person recruitment the week prior to focus groups by passing out flyers, completing eligibility screenings, and registering participants on-site, focusing on high-traffic public areas providing resources that low-SES individuals are likely to access, such as bus stops and libraries. Each participant signed a printed consent form on-site prior to beginning the focus group and received a $\$ 50$ incentive. The study protocol was approved by the institutional review board at the University of North Carolina at Chapel Hill (Study No. 4-0651).

\section{Focus Groups}

Eight focus groups, each including between 10 and 16 participants, were held at public library locations. Sessions were conducted by a third party moderator with extensive focus group experience; the moderator was not involved in data analysis or interpretation. Focus groups were semistructured, based on a question guide developed by study authors. Groups lasted between 60 and 90 minutes. Initial questions focused on barriers and motivators for quitting and assessing awareness and opinions of cessation resources available, specifically the telephone quitline. Participants were asked to recall any quit smoking or smoking prevention advertisements they had ever seen and asked to describe how they felt when they saw the ads and how the ads affected their thoughts about smoking or quitting smoking. Participants were then shown five television ads from various state-level campaigns (2009 ad from North Carolina's Tobacco. Reality. Unfiltered campaign, 2009 ad from Washington State's Dear Me campaign, 2012 ad from New York City's Suffering Every Minute campaign, and a 2009 North Carolina Quitline promotion campaign) and one ad from the 2013 national Tips campaign. Ads were shown one at a time with a set of discussion questions after each ad. Ads were selected based on no-fee availability from the CDC Media Campaign Resource Center and represented a mix of themes and tones (i.e., some used graphic health imagery while others focused on self-efficacy or the benefits of quitting). To our knowledge, no studies have been published investigating the impact of these campaigns on differing socioeconomic groups.

\section{Analysis}

All focus groups were audiotaped and transcribed verbatim and imported into ATLAS.ti 6.2 (Scientific Software Development GmbH). Four research team members were involved in an iterative review process of the data, using an inductive thematic analysis approach (Braun \& Clarke, 2006). Two of these team members attended the focus groups as note-takers. Team members first read through two transcripts to become familiar with the data, followed by team discussion to clarify the research question and develop initial codes. Team members read through the same two transcripts a second and third time, with a team meeting after each to review coding and finalize the codebook to add or remove codes that did not add value to the analytic process. A fourth round of reading involved each team member coding two new transcripts with the finalized codebook. Two team members then reviewed each transcript to merge coding and reach consensus on different applications of codes as needed. Inconsistencies in coding between team members were resolved through discussion. The four analysis team members collaboratively reviewed final coding to create a thematic map of the codes, as described by Braun and Clarke (2006), which was used as a basis for defining and refining themes across the data set. Identification of overarching themes was based on consensus that the idea was expressed across multiple participants and groups and that it captured an important part of the narrative of how low-SES smokers receive and evaluate tobacco cessation media messages.

\section{RESULTS}

A total of 98 adults who reported current cigarette smoking participated in the eight focus groups (Table 1). Demographic data were missing for $21 \%$ to $33 \%$ of participants due to refusals and difficulty monitoring data completion during in-person recruiting. Though factors related to SES were not a part of eligibility criteria, most participants reported lower educational attainment (55\% reported high school/GED or less). Only $27 \%$ of participants indicated they had "enough money to pay the bills," and discussion of financial stressors was common across all groups. Discussion across specific topics centered around two themes that appeared to influence participants' evaluation of ads: skepticism about cessation media messages and resources and perceived barriers to quitting.

\section{Skepticism}

Many participants expressed skepticism about the content of tobacco control ads, the role of the tobacco 
TABLE 1

Summary of Participant Demographics $(N=98)$

\begin{tabular}{|c|c|}
\hline Demographic Characteristic & $\mathrm{n}(\%)$ \\
\hline \multicolumn{2}{|l|}{ Gender } \\
\hline Female & $27(27.6)$ \\
\hline Male & $50(51.0)$ \\
\hline Unknown & $21(21.4)$ \\
\hline \multicolumn{2}{|l|}{ Age, years } \\
\hline $18-24$ & $5(5.1)$ \\
\hline $25-34$ & $22(22.5)$ \\
\hline $35-54$ & $36(36.7)$ \\
\hline $55+$ & $14(14.3)$ \\
\hline Unknown & $21(21.4)$ \\
\hline \multicolumn{2}{|l|}{ Race } \\
\hline White & $17(17.3)$ \\
\hline Black or African American & $29(29.6)$ \\
\hline Other & $25(25.5)$ \\
\hline Unknown & $27(27.6)$ \\
\hline \multicolumn{2}{|l|}{ Ethnicity } \\
\hline Hispanic or Latino & $23(23.5)$ \\
\hline Not Hispanic or Latino & $41(41.8)$ \\
\hline Unknown & $34(34.7)$ \\
\hline \multicolumn{2}{|l|}{ Sexual orientation } \\
\hline Heterosexual/straight & $59(60.2)$ \\
\hline Lesbian, gay, or bisexual & $6(6.1)$ \\
\hline Other & $1(1.0)$ \\
\hline Unknown & $32(32.7)$ \\
\hline \multicolumn{2}{|l|}{ Education level } \\
\hline Less than high school & $17(17.3)$ \\
\hline High school/GED & $37(37.8)$ \\
\hline Some college/college or more & $17(17.3)$ \\
\hline Unknown & $27(27.6)$ \\
\hline \multicolumn{2}{|l|}{ Financial situation } \\
\hline Have enough money to pay the bills & $27(27.6)$ \\
\hline Have to cut back on things to pay the bills & $8(8.2)$ \\
\hline Have trouble paying the bills & $23(23.5)$ \\
\hline Unknown & $40(40.8)$ \\
\hline
\end{tabular}

industry and governmental agencies in sponsoring media messages and promoting continued tobacco use, and the safety and efficacy of cessation supports. Such skepticism appeared to be salient in how they evaluated tobacco control media messages.

Content of Tobacco Control Ads. Participants' skepticism about the content of tobacco control ads focused particularly on ads depicting the serious health consequences of smoking. Some participants expressed doubt about the legitimacy of testimonial style ads, asserting that these ads tried to pass off actors as "real" people sharing their stories and that the health effects portrayed were rare cases, overly extreme, or unlikely to have been caused solely by smoking.

I mean, I seen a lot of people that passed away with trachs because it was cancer. You know, it wasn't some that smoked cigarettes, but it was because of cancer. They had other . . . form[s] of cancer so how would you know? Like, they could be just using people that are saying like what their illness is, but it's not really caused from smoking. (Female, Group 4)

Distrust of the Tobacco Industry and Government. Participants also expressed distrust and negative attitudes about the tobacco industry's and government entities' perceived roles in sponsoring tobacco control campaigns. Some discussion was given to the idea that tobacco control efforts may be sponsored by the tobacco industry, making ads untrustworthy due to conflicts of interest between maintaining sales and encouraging people to quit. Other discussion focused on perceptions that government entities are too invested in maintaining revenue from tobacco sales and/or too connected to the tobacco industry to truly want people to quit smoking.

$$
\begin{aligned}
& \text { If you make it illegal, I mean not to be-the govern- } \\
& \text { ment makes too much money on cigarettes for them } \\
& \text { to stop selling cigarettes. The government, I mean, } \\
& \text { you've got medical. You've got doctors. You've got, } \\
& \text { you know, there's too much money involved for } \\
& \text { them to say let's stop smoking. (Male, Group 2) }
\end{aligned}
$$

A related vein of discussion focused on the perception that large amounts of money from tobacco sales revenue and tobacco industry lawsuits are available for campaigns but that only a bare minimum is allocated, resulting in ads that are lower quality and ineffective.

Safety and Efficacy of Cessation Supports. Finally, skepticism about tobacco control media messages appeared to be intertwined with skepticism about cessation supports, such as the quitline and tobacco cessation pharmacotherapy. Lack of knowledge about available supports played some role in the skepticism, with most participants indicating they did not know what the quitline offered or had never heard of the quitline, despite the quitline number being included in many of the ads participants recalled seeing. 
I now realize that I've seen [the quitline number], but I've overlooked it so much. You know what I mean? Because I've definitely seen commercials with the quitline number, but thinking about it when you first started talking about it, it didn't register in my brain. (Male, Group 5)

Even after services were described by the moderator, many participants expressed skepticism that such services would be helpful or judgment-free.

Skepticism about cessation supports was also related to feeling that such resources were not truly accessible or doubt that supports provided for free (e.g., coaching, 2 weeks of free nicotine patches) would be sufficient to meaningfully aid in long-term quitting. Skepticism about cessation medication was also related to uncertainty or misinformation about the safety and efficacy of NRT and prescription cessation pharmacotherapy.

\section{Barriers to Quitting}

Stress. Participants described multiple barriers to quitting, which were closely linked to or embedded in participants' social and environmental contexts. Participants described living in highly stressful circumstances and identified stress as a primary barrier to quitting. Participants described a cyclical process about how another barrier to quitting-the lack of societal support and resources for tobacco use cessation-led to more stress. At the same time, smoking was described as an important, or even the only, perceived source of coping with stressors and was used as a substitute or replacement for other stress responses or as a type of self-medication.

[Smoking] is anger management. It's medicinal in my mind. Helping my anger management when I'm stressed, I'm angry. Instead of doing what I want to do, I'll smoke a cigarette . . . like if I'm depressed or something like that. (Male, Group 2)

Social Environment. Many participants described their motivation to quit smoking being undermined by support networks and social environments (e.g., families, recovery groups) that are saturated with other people who smoke. Some participants described how smoking was a normative part of their family culture and discussed the lack of social support for quitting that exists in their environments where smoking prevalence is high.

It's a habit . . . if you have other people around you that smoke and you're trying to quit, it's not going to be easy, because you're not smoking it, but you're smelling it constantly, you're seeing other people smoking. (Female, Group 7)

Smoking was so ubiquitous in many participants' lives that they perceived no way to avoid it. Indeed, several participants shared that their only successful quit attempts had occurred during incarceration when their environments were mandated to be tobacco-free, describing quick relapse to smoking after being released.

Addiction. Many participants focused on the role addiction played in their perceived inability to quit, describing addiction as an insurmountable barrier. There was consensus across most participants that their relationship with smoking was rooted in addiction, and some participants shared stories of how quitting smoking was more difficult for them than quitting other drugs.

It's physically addictive too, you know. The physical addiction to it is intense. I've dealt with other addiction issues in my life, and that is by far the hardest one. (Male, Group 5)

Participants described a disconnect between the tobacco control messages they hear and their everyday struggle with nicotine addiction; participants perceived messages as not acknowledging the seriousness of their addiction and the help they need to overcome that addiction. A few participants even expressed a desire for a rehabilitation program similar to treatment for other drugs, such as Alcoholics Anonymous, specific for nicotine addiction

See Table 2 for a list of illustrative quotes around the two themes.

\section{DISCUSSION}

Our findings support and expand on previous research, suggesting that population-based tobacco control media campaigns may be less effective among smokers from lower SES populations (Niederdeppe et al., 2011). Most participants had been exposed to one or more cessation media campaigns, suggesting that campaign reach may not be the sole driver of effectiveness. Our findings suggest that a more nuanced response among lower SES smokers, in which skepticism and significant perceived barriers to quitting contribute to dismissal of and/or resistance to population-based media campaigns.

For many participants in these groups, the graphic and negative aspects of the ads did not appear to translate into 
TABLE 2

Qualitative Themes Regarding Perceptions of Tobacco Cessation Media Messages (Sampling of Illustrative Quotes)

Domain Qualitative Themes Illustrative Quotes

Skepticism about Content of tobacco messages

control ads
Distrust of the

tobacco industry

and government

Safety and efficacy of cessation supports
"I mean, I seen a lot of people that passed away with trachs because it was cancer. You know, it wasn't some that smoked cigarettes, but it was because of cancer. They had other . . . form[s] of cancer so how would you know? Like, they could be just using people that are saying like what their illness is, but it's not really caused from smoking." (Female, Group 4)

"Sometimes I feel indifferent because I don't know what that person [from the ad] could have done to even cause that level of cancer. They could have been smoking crazy packs a day which is not something I do." (Male, Group 6)

"I feel like with the commercials and everything, all the movies we see and everything, they could be actors. Even if they do get somebody real, we don't really know that because we know everything is fantasized on TV most of the time anyway and special effects we see all the time. I mean you could take somebody and make them look like whatever you want to make them look like for special effects.” (Male, Group 6)

"Tobacco is a big business, just like insurance . . . big business, big money, they got too much power . . . any time there's big money in stuff, cigarettes are going to be around forever.” (Male, Group 8)

"It's a manmade, I mean, it's part of government. The government put that out there. I mean, they could never make money unless they put a product out there that they know people's going to try it, and they're going to get addicted to it.” (Female, Group 4)

“The people that's making money off [tobacco], they don't want you to quit." (Male, Group 7)

"If you make it illegal, I mean not to be-the government makes too much money on cigarettes for them to stop selling cigarettes. The government, I mean, you've got medical. You've got doctors. You've got, you know, there's too much money involved for them to say let's stop smoking." (Male, Group 2)

“. . . I don't want to talk to someone who has no idea of what I'm going through. You could have learned and have book smarts about what smoking is, but if you've never smoked you don't know." (Male, Group 5)

"It's not that we don't want to quit. It's that we don't have the resources or the help." (Female, Group 6)

"They [nicotine patches] have a chemical that will help you stop smoking cigarettes, but how would you know if it's going to harm you more than the cigarettes?" (Female, Group 4)

"I now realize that I've seen [the quitline number], but I've overlooked it so much. You know what I mean? Because I've definitely seen commercials with the quitline number, but thinking about it when you first started talking about it, it didn't register in my brain.” (Male, Group 5)

"[The quitline] is going to give you 2 weeks [of patches] but what's going to happen then? Then how much is it going to cost you?” (Male, Group 6) 
TABLE 2 (CONTINUED)

\begin{tabular}{|c|c|c|}
\hline Domain & Qualitative Themes & Illustrative Quotes \\
\hline \multirow[t]{11}{*}{$\begin{array}{c}\text { Barriers to } \\
\text { quitting }\end{array}$} & \multirow[t]{3}{*}{ Stress } & $\begin{array}{l}\text { "When you have a Newport, you can actually get a high. Like you get } \\
\text { that kind of a high a lot of times. And sometimes when you smoke a } \\
\text { Newport, you'd be mad, upset, stressed or whatever-it calms you } \\
\text { down." (Male, Group 5) }\end{array}$ \\
\hline & & $\begin{array}{l}\text { "The stress builds up so much to the point I'm not even thinking about } \\
\text { calling [the quitline]. I probably will be thinking about cigarettes." } \\
\text { (Male, Group 8) }\end{array}$ \\
\hline & & $\begin{array}{l}\text { “[Smoking] is anger management. It's medicinal in my mind. Helping } \\
\text { my anger management when I'm stressed, I'm angry. Instead of doing } \\
\text { what I want to do, I'll smoke a cigarette . . . like if I'm depressed or } \\
\text { something like that.” (Male, Group 2) }\end{array}$ \\
\hline & \multirow[t]{4}{*}{ Social environment } & $\begin{array}{l}\text { “It's a habit . . . if you have other people around you that smoke and } \\
\text { you're trying to quit, it's not going to be easy, because you're not } \\
\text { smoking it, but you're smelling it constantly, you're seeing other } \\
\text { people smoking.” (Female, Group 7) }\end{array}$ \\
\hline & & $\begin{array}{l}\text { "I left the cigarettes at the house and don't want to bring them with me } \\
\text { because I'm trying to quit and I'll be downtown or I'll be somewhere } \\
\text { and I'll see somebody smoking, like, 'Dang, I wish I was smoking."” } \\
\text { (Female, Group 7) }\end{array}$ \\
\hline & & $\begin{array}{l}\text { "The thing about quitting is I could go like a couple of days without a } \\
\text { cigarette but the second you go outside because it's like everywhere so } \\
\text { it's not that easy because to be honest if you enjoy cigarettes." (Male, } \\
\text { Group 6) }\end{array}$ \\
\hline & & $\begin{array}{l}\text { "I grew up in a household where everyone smoked, and as a kid I } \\
\text { remember thinking to myself eventually I'm going to do that, or I want } \\
\text { that, or is that what I'm going to do when I'm older, is that what } \\
\text { growing up is all about? And when I was in school and my friends } \\
\text { were hanging out behind the tennis court smoking, I was like, oh so } \\
\text { it's my time to grow up." (Female, Group 7) }\end{array}$ \\
\hline & \multirow[t]{4}{*}{ Addiction } & $\begin{array}{l}\text { "It's physically addictive too, you know. The physical addiction to it is } \\
\text { intense. I've dealt with other addiction issues in my life, and that is by } \\
\text { far the hardest one." (Male, Group 5) }\end{array}$ \\
\hline & & $\begin{array}{l}\text { "Cigarettes is not something that people say okay I just kind of smoke. } \\
\text { It's an addiction that's really hard to deal with. It's like being an } \\
\text { alcoholic, being a drug addict." (Female, Group 6) }\end{array}$ \\
\hline & & $\begin{array}{l}\text { "It's like binge drinking, I mean, I pick up-I don't know why I pick up, } \\
\text { I pick up because I feel like picking up a cigarette. And if you ask me } \\
\text { what it does to me, I can’t say, I just-all I know is I'm addicted and I } \\
\text { want to stop.” (Male, Group 7) }\end{array}$ \\
\hline & & $\begin{array}{l}\text { "And as a fact for rehab, I was there for alcohol, and the alcohol I beat } \\
\text { in } 2 \text { weeks, I couldn't stop thinking about cigarettes. The cigarette was } \\
\text { more addictive for me, personally." (Male, Group 8) }\end{array}$ \\
\hline
\end{tabular}

perceived effectiveness. Indeed, these aspects of the ads contributed to feelings of skepticism about message content, which some participants described as exaggerated or unrealistic. This skepticism contributed to participants evaluating ads with a self-exempting lens, focusing on ways in which the people and circumstances depicted in ads do not reflect their reality. As such, the credibility of both the ads' explicit (e.g., smoking leads to severe negative health consequences) and implicit (e.g., this could happen to you) messages 
was undermined. These findings are consistent with self-exempting, or risk-minimizing, beliefs that arise when an individual's actions conflict with his or her knowledge about those actions (i.e., cognitive dissonance theory; Guillaumier et al., 2016). Many participants in these focus groups expressed "skeptic" self-exempting beliefs (i.e., they do not believe the harms of smoking portrayed in messages are real), as well as "bulletproof" beliefs (i.e., they will not be affected by the harms of smoking portrayed in messages, often because they perceived themselves as smoking less than the actor portrayed; Oakes et al., 2004). As seen in our focus groups, smokers with lower educational attainment are more likely to hold selfexempting or other "disengagement" beliefs (Oakes et al., 2004), which have been linked to lower motivation and intentions to quit (Kleinjan, van den Eijnden, Dijkstra, Brug, \& Engels, 2006; Oakes et al., 2004).

Our results are consistent with previous research that indicates perceived credibility of the source of tobacco control campaigns plays an important role in campaign effectiveness (Schmidt, Ranney, Pepper, \& Goldstein, 2016). Trust in the source of health information is suggested to affect how that information is received, processed, and acted on (Avery, 2010), and trustworthiness has been identified as a key component of source credibility (Schmidt et al., 2016). In some groups, there was confusion about the source of messages, with discussion given to the idea that some messages are sponsored by the tobacco industry and are therefore neither trustworthy nor credible. The idea that messages encouraging participants to quit might be sponsored by the same entities that are profiting off their addiction appeared to leave some participants feeling resigned or disempowered, suggesting that this kind of misinformation may further undermine message effectiveness by contributing to reduced self-efficacy for quitting. This perception is not entirely unfounded, considering that the tobacco industry has historically targeted low-SES and minority groups (Balbach, Gasior, \& Barbeau, 2003; Yerger, Przewoznik, \& Malone, 2007).

Other participants correctly identified governmental agencies as the source of tobacco control campaigns but believed that government entities were invested in ensuring that people continue to smoke in order to satisfy the government's relationships with the tobacco industry and/or to continue bringing in revenue from tobacco sales. As such, government entities were perceived to be untrustworthy as sources of credible, motivating messages about quitting smoking. Our results suggest that clearly communicating the source of tobacco control campaigns and working to correct misperceptions about the relationship between the tobacco industry and governmental public health and regulatory agencies may contribute to increased trust in these agencies among low-SES smokers. As such, according to Carey's transmission and ritual view of communication, addressing the historical practice of targeting lowSES and minority individuals by the tobacco industry (Balbach et al., 2003; Yerger et al., 2007) and correcting misinformation related to message sponsorship may help alter the selective perception of the message transmitted, or the meaning individuals derive from the message (Rimal \& Lapinski, 2009).

Lack of knowledge and skepticism about the accessibility, efficacy, and safety of evidence-based cessation supports like the quitline and cessation pharmacotherapy also appeared to influence participants' evaluation of and receptivity to tobacco control media campaign messages. Distrust of quitline services (Sheffer, Brackman, Cottoms, \& Olsen, 2011) and beliefs that evidence-based treatments are not more effective than other methods (McMenamin, Halpin, \& Bellows, 2006); that cessation pharmacotherapy is addictive, dangerous, and not effective (Cummings et al., 2004; Wiltshire, Bancroft, Parry, \& Amos, 2003); and that cessation treatments are difficult to access (McMenamin et al., 2006; Roddy, Antoniak, Britton, Molyneux, \& Lewis, 2006) are well documented among low-SES smokers. Our findings add to this literature and suggest that negative perceptions and lack of knowledge about evidence-based cessation supports may lessen the potential motivational impact of cessation messages. Additional research is needed to more clearly understand this process and to determine how mass media messages can communicate information about cessation treatment resources in a way that reduces misperceptions and skepticism among low-SES smokers. Increasing the duration of time for which quitline numbers or other resources are displayed on ads, including a brief description about how quitlines work and brief statements debunking common myths about the safety and efficacy of NRT, and offering longer courses of free NRT, may be effective strategies for future media campaigns to consider. Increasing knowledge around the availability of tobacco cessation resources such as the quitline and the effectiveness of these resources can increase self-efficacy beliefs among tobacco users, resulting in a more positive selective perception of media campaign messages (Rimal \& Lapinski, 2009).

Findings suggest that participants' personal experiences, particularly related to stress and addiction, and social norms around smoking in low-SES populations also affect the selective perception of tobacco control media messages (Rimal \& Lapinski, 2009). Skepticism about cessation resources was closely linked to the 
ways in which smoking permeates their social environments, the importance of smoking as a critical stress management tool, and strong addiction to nicotine. These perceived barriers align with other documented contributors to tobacco use and cessation disparities among people with low SES: lack of social support for quitting, more prosmoking social norms, higher stress environments, greater reliance on smoking as a coping mechanism, and stronger addiction (Hiscock et al., 2012). The extent to which participants talked about these barriers to quitting suggests that these barriers may mediate the motivational impact of messages, even when the messages are attention-grabbing and successfully elicit negative emotional reactions. Barriers related to low-SES smokers' environments and experiences with stress are likely strongly influenced by more "upstream" challenges, such as low wages and lack of affordable housing, that are beyond the reach of tobacco control programs. However, it may be important for media campaigns to acknowledge these barriers to better reflect the realities of low-SES smokers' lives and challenges with quitting (i.e., their selective perception) and potentially reduce resistance to cessation messages (Rimal \& Lapinski, 2009).

Participants' perceptions about nicotine addiction as a significant barrier to quitting reflect evidence that low-SES smokers are more highly addicted than higher SES smokers and that higher addiction is related to reduced likelihood of quitting (Hiscock et al., 2012). Some participants expressed feeling frustrated that tobacco control messages do not adequately reflect the realities of nicotine addiction, a disconnect that may increase the chances of low-SES smokers viewing ads through a self-exempting lens. The belief that quitting smoking is as difficult as or more difficult than overcoming other addictions contributed to a feeling among some participants that the kind of help they would need to quit smoking (e.g., detox programs or long-term support programs) is not available, contributing to skepticism about available cessation resources. As such, believing that nicotine addiction is an insurmountable barrier to quitting appeared to reinforce resistance to cessation-focused campaign messages. It may be important for tobacco control media campaigns to increase low-SES smokers' efficacy beliefs by validating their experience with addiction and communicating that nicotine addiction can be overcome with available evidence-based treatments.

\section{Limitations}

The focus groups were originally conducted to inform the Connecticut Tobacco Control Program mass communication strategy, with a focus on program planning and evaluation. As such, we used a convenience sample of adult smokers, with no specific inclusion criteria based on SES, and our participant demographic information was incomplete for a substantial number of participants. Based on available data, though, the majority of participants had low education levels and/ or were struggling financially and thus represented the intended population. Though qualitative data are not intended to be generalizable, we recognize that results from this particular study may not necessarily be applicable to all low-SES smokers in the United States. Additional studies can help clarify the extent to which skepticism and barriers to quitting influence the receptiveness of tobacco control media messages among lowSES smokers across the country.

\section{Conclusions}

As tobacco use is increasingly concentrated in lowSES populations, it is critical that tobacco control mass media campaigns are appropriately targeted to this priority group. Findings from our focus groups add to the body of research indicating that tobacco control messaging may reach lower income smokers but does not appear to effectively motivate this group to quit. Our findings suggest that skepticism about cessation message content, perceived sources of campaign ads, and cessation supports as well as barriers to quitting related to stress, social contexts, and addiction play a role in how low-SES smokers evaluate tobacco control media messages. Further research examining the ways in which media campaigns can address skepticism and barriers to quitting among low-SES smokers may inform more effective campaigns.

\section{REFERENCES}

Avery, E. J. (2010). The role of source and the factors audiences rely on in evaluating credibility of health information. Public Relations Review, 36, 81-83.

Balbach, E. D., Gasior, R. J., \& Barbeau, E. M. (2003). RJ Reynolds' targeting of African Americans: 1988-2000. American Journal of Public Health, 93, 822-827.

Braun, V., \& Clarke, V. (2006). Using thematic analysis in psychology. Qualitative Research in Psychology, 3, 77-101.

Centers for Disease Control and Prevention. (2014). Best practices for comprehensive tobacco control programs-2014. Atlanta, GA: Centers for Disease Control and Prevention, National Center for Chronic Disease Prevention and Health Promotion, Office on Smoking and Health.

Clegg, L. X., Reichman, M. E., Miller, B. A., Hankey, B. F., Singh, G. K., Lin, Y. D., . . Chen, V. W. (2009). Impact of socioeconomic status on cancer incidence and stage at diagnosis: Selected findings from the surveillance, epidemiology, and end results: 
National longitudinal mortality study. Cancer Causes \& Control, 20, 417-435.

Cummings, K. M., Hyland, A., Giovino, G. A., Hastrup, J. L., Bauer, J. E., \& Bansal, M. A. (2004). Are smokers adequately informed about the health risks of smoking and medicinal nicotine? Nicotine \& Tobacco Research, 6(Suppl. 3), S333-S340.

Durkin, S., Brennan, E., \& Wakefield, M. (2012). Mass media campaigns to promote smoking cessation among adults: An integrative review. Tobacco Control, 21, 127-138. doi:10.1136/ tobaccocontrol-2011-050345

Geller, A. C., Rees, V. W., \& Brooks, D. R. (2016). The proposal for smoke-free public housing: Benefits, challenges, and opportunities for 2 million residents. Journal of the American Medical Association, 315, 1105-1106.

Guillaumier, A., Bonevski, B., Paul, C., D’Este, C., Twyman, L., Palazzi, K., \& Oldmeadow, C. (2016). Self-exempting beliefs and intention to quit smoking within a socially disadvantaged Australian sample of smokers. International Journal of Environmental Research and Public Health, 13, 118. doi:10.3390/ ijerph13010118

Ham, D. C., Przybeck, T., Strickland, J. R., Luke, D. A., Bierut, L. J., \& Evanoff, B. A. (2011). Occupation and workplace policies predict smoking behaviors: Analysis of national data from the current population survey. Journal of Occupational and Environmental Medicine, 53, 1337-1345. doi:10.1097/JOM.0b013e3182337778

Hiscock, R., Bauld, L., Amos, A., Fidler, J. A., \& Munafò, M. (2012). Socioeconomic status and smoking: A review. Annals of the New York Academy of Sciences, 1248, 107-123.

Hu, S. S., Neff, L., Agaku, I. T., Cox, S., Day, H. R., Holder-Hayes, E., \& King, B. A. (2016). Tobacco product use among adultsUnited States, 2013-2014. Morbidity and Mortality Weekly Report, 65, 685-691. doi:10.15585/mmwr.mm6527a1

Kleinjan, M., van den Eijnden, R. J., Dijkstra, A., Brug, J., \& Engels, R. C. (2006). Excuses to continue smoking: The role of disengagement beliefs in smoking cessation. Addictive Behaviors, 31, 2223-2237.

Kotz, D., \& West, R. (2009). Explaining the social gradient in smoking cessation: It's not in the trying, but in the succeeding. Tobacco Control, 18, 43-46. doi:10.1136/tc.2008.025981

McAfee, T., Davis, K. C., Alexander, R. L., Jr., Pechacek, T. F., \& Bunnell, R. (2013). Effect of the first federally funded US antismoking national media campaign. The Lancet, 382, 20032011.

McCarthy, M., Siahpush, M., Shaikh, R. A., Kessler, A. S., \& Tibbits, M. (2016). Social disparities in unaided quit attempts among daily current and former smokers: Results from the 20102011 tobacco use supplement to the current population survey. Nicotine \& Tobacco Research, 18, 1705-1710.

McMenamin, S. B., Halpin, H. A., \& Bellows, N. M. (2006). Knowledge of Medicaid coverage and effectiveness of smoking treatments. American Journal of Preventive Medicine, 31, 369374.

Mucha, L., Stephenson, J., Morandi, N., \& Dirani, R. (2006). Metaanalysis of disease risk associated with smoking, by gender and intensity of smoking. Gender Medicine, 3, 279-291.
Niederdeppe, J., Farrelly, M. C., Nonnemaker, J., Davis, K. C., \& Wagner, L. (2011). Socioeconomic variation in recall and perceived effectiveness of campaign advertisements to promote smoking cessation. Social Science \& Medicine, 72, 773-780. doi:10.1016/j.socscimed.2010.12.025

Niederdeppe, J., Kuang, X., Crock, B., \& Skelton, A. (2008). Media campaigns to promote smoking cessation among socioeconomically disadvantaged populations: What do we know, what do we need to learn, and what should we do now? Social Science \& Medicine, 67, 1343-1355. doi:10.1016/j.socscimed.2008.06.037

Oakes, W., Chapman, S., Borland, R., Balmford, J., \& Trotter, L. (2004). "Bulletproof skeptics in life's jungle": Which self-exempting beliefs about smoking most predict lack of progression towards quitting? Preventive Medicine, 39, 776-782.

Paul, C. L., Turon, H., Bonevski, B., Bryant, J., \& McElduff, P. (2013). A cross-sectional survey of experts' opinions about the relative effectiveness of tobacco control strategies for the general population versus disadvantaged groups: What do we choose in the absence of evidence? BMC Public Health, 13, 1144. doi:10.1186/1471-2458-13-1144

Rimal, R. N., \& Lapinski, M. K. (2009). Why health communication is important in public health. Bulletin of the World Health Organization, 87, 247.

Roddy, E., Antoniak, M., Britton, J., Molyneux, A., \& Lewis, S. (2006). Barriers and motivators to gaining access to smoking cessation services amongst deprived smokers: A qualitative study. BMC Health Services Research, 6(1), 147.

Schmidt, A. M., Ranney, L. M., Pepper, J. K., \& Goldstein, A. O. (2016). Source credibility in tobacco control messaging. Tobacco Regulatory Science, 2, 31-37.

Sheffer, C. E., Brackman, S. L., Cottoms, N., \& Olsen, M. (2011). Understanding the barriers to use of free, proactive telephone counseling for tobacco dependence. Qualitative Health Research, 21, 1075-1085. doi:10.1177/1049732311404248

Siahpush, M., McNeill, A., Borland, R., \& Fong, G. T. (2006). Socioeconomic variations in nicotine dependence, self-efficacy, and intention to quit across four countries: Findings from the international tobacco control (ITC) four country survey. Tobacco Control, 15(Suppl. 3), iii71-iii75. doi:15/suppl_3/iii71

Wiltshire, S., Bancroft, A., Parry, O., \& Amos, A. (2003). "I came back here and started smoking again”: Perceptions and experiences of quitting among disadvantaged smokers. Health Education Research, 18, 292-303.

Yerger, V. B., Przewoznik, J., \& Malone, R. E. (2007). Racialized geography, corporate activity, and health disparities: Tobacco industry targeting of inner cities. Journal of Health Care for the Poor and Underserved, 18, 10-38.

Zhang, L., Malarcher, A., Babb, S., Mann, N., Davis, K., Campbell, K., . . . Rodes, R. (2015). The impact of a national tobacco education campaign on state-specific quitline calls. American Journal of Health Promotion, 30, 374-381.

Zhang, L., Vickerman, K., Malarcher, A., \& Carpenter, K. (2015). Changes in quitline caller characteristics during a national tobacco education campaign. Nicotine \& Tobacco Research, 17, 1161-1166. doi:10.1093/ntr/ntu271 